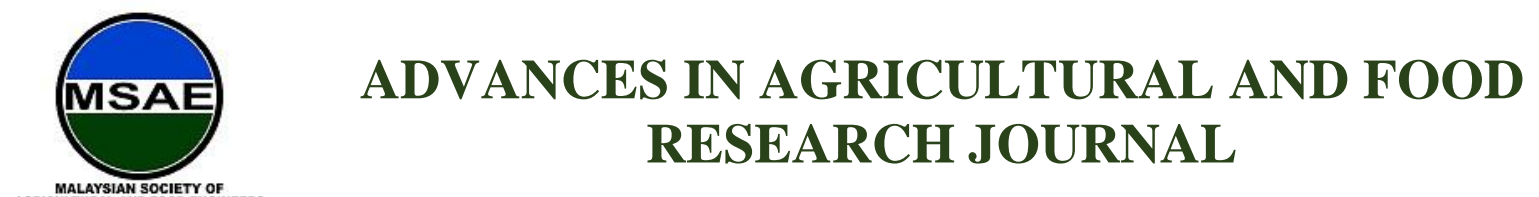

HH PUBLISHER

Original Research Article

\title{
Impacts of Fertigation Via Surface and Subsurface Drip Irrigation on Growth Rate of Rockmelon
}

\author{
Wan Fazilah Fazlil Ilahi ${ }^{1 *}$, Nik Norasma Che'Ya ${ }^{1}$,Muhamad Faris Abdillah Razali . ${ }^{1}$, Nur Hidayu Abu \\ Hassan $^{1}$ \\ ${ }^{1}$ Department of Agriculture Technology, Faculty of Agriculture, Universiti Putra Malaysia, 43400 Serdang, \\ Selangor, Malaysia. \\ *Corresponding author: Fazilah W. F. F., Department of Agriculture Technology, Faculty of Agriculture, \\ Universiti Putra Malaysia, 43400 Serdang, Selangor, Malaysia; wanfazilah@upm.edu.my
}

\begin{abstract}
Fertigation is one of the most important application of irrigation that are being used in commercial farming. This aplication help farmers to timely supply the water through drip irrigation coupled with accurate amout of water, rate of fertilizer application, and at the same time improving the nutrient uptake and water use efficiency (WUE) by the plant. The water supply through surface and subsurface drip irrigation systems are the most efficient irrigation practice compared to others. Water supply from subsurface drip irrigation system is directly into the root zone, while for surface drip irrigation, water is supplied above the root zone. However, the use of surface drip irrigation system can cause the irrigation water easily evaporate to environment and reduce the WUE by plant. Rockmelon (cucumis melo) was selected as plant material in this study. Rockmelon is one of the plant that contain sweet and juicy along with other nutritional value. It also has commercial interest in a number of countries, including Europe, United States, Mediterranean and Asia. The objectives of the study were to observe the different growth rate of rockmelon between surface and subsurface drip irrigation as well as to observe the efficiency of irrigation. This study was conducted under the rain shelter at Unit Fertigasi Projek Keusahawanan Ladang 10, Universiti Putra Malaysia (UPM). There were two treatments of irrigation tested, surface and subsurface drip irrigations. Data collection include leaf diameter, leaf length and fruit circumferences. The effect of irrigation on growth performance of rockmelon were observed during week one and week six and was analyzed with Statistically Analysis System (SAS). The result of this study showed that, the growth for surface drip irrigation is higher compared to subsurface drip irrigation and both treatments achieved $25 \%$ of irrigation application efficiency.
\end{abstract}

Keywords: rockmelon; fertigation; surface irrigation; subsurface irrigation; cocopeat

Received: $6^{\text {th }}$ October 2020

Accepted: $6^{\text {th }}$ November 2020

Available Online: $20^{\text {th }}$ November 2020

Citation: Fazilah WFF, Norasma CYN., Abdillah $\mathrm{RMF}$, et al. Impacts of fertigation via surface and subsurface drip irrigation on growth rate of rockmelon. Adv Agri Food Res J 2020; 1(2): a0000134. https://doi.org/10.36877/aafrj.a0000134

\section{Introduction}

Irrigation is one of the vital aspects in crop production, for example most of the crop species heavily rely on water as source of food for nutrients uptake, food production and 
transpiration. However, in many countries with sacred and limited water resources, providing water to crop is one of the major issues and globally are aiming to get the highest water usage and application. Water use efficiency must be improved for the better safeguard of food security because of the enormous contribution of the increasing crop production. Moreover, fertilizer has been used in every region of the world and the application has been enhanced by the farmers all over the world (Wu et al., 2019).

Over the years, with the improvement and enhancement in technology, fertigation has increasingly developed and used by the farmers. Increasing water rivalry between rural, industrial and urban consumers makes it necessary to continually improve irrigation in commercial agriculture and effective management techniques can help to improve efficiency of plant water by scheduling correctly and applying fertilization water (Çolak et al., 2018). Therefore, maximum fertigation efficiency requires knowledge of crop nutrient requirements, soil nutrient supply and injection technology of fertilizers, irrigation schedule, crop and soil monitoring techniques. Fertilization by drip irrigation can reduce overall fertilizer application levels if properly managed and reduce the adverse environmental impact of production (Sidhu et al., 2019).

Drip irrigation is one of the methods that has been used in fertigation and can be applied as surface and subsurface irrigation systems. The fertilizer and irrigation water are distributed through the system to increase the efficiency of fertilizer use to raise crops. Furthermore, it can increase nutrient uptake and plant water while reducing nutrient leaching. In addition, different method such as surface drip irrigation and subsurface drip irrigation, can contribute to varying the effect on water and nutrient distribution. Wu et al. (2019) reported that the subsurface shifted the root density to a deeper depth and had increased annual yield compared to surface drip irrigation.

Melon is normally irrigated by methods of furrow or drip. Similar yields could be achieved with both methods in soils with considerably high water holding capacity and under complete irrigation, but irrigation water requirements decrease and water usage output increases with drip irrigation and using drip irrigation can increase fruit size and marketable yield, as well as early harvesting in sandy soils (Şengül et al., 2014). The use of techniques such as drip irrigation and fertigation through subsurface method with mulching may contribute to the water and nutrient productivity in melon production due to reduction of the accumulation of water and fertilizer salts in the soil surface. This technique allows good water and nutrition application to the melon crop, minimizing the effects of atmospheric evaporative demand, improving the quality and melon yield, better water and nutrients spatial distribution in the roots also reducing the environmental impact by excessive fertilization (Monteiro et al., 2014). The study conducted by Monteiro et al. (2014) found that between surface and $0.40 \mathrm{~m}$ drip irrigation, the crop with $0.40 \mathrm{~m}$ underground drip resulted in better water productivity in sandy loam and clay planted in rows. This was due to the application of water next to the roots and thus reduced loss due to evaporation. There is a need for further studies to decide about the feasibility of using fertigation with surface or subsurface irrigation 
for individual melon planted in polybags with soilless media as this method is widely practiced in Malaysia. Therefore, the objectives of the study were to observe the different growth rate of rockmelon and efficiency between surface and subsurface drip irrigations for soilless media in polybags.

\section{Materials and Methods}

\subsection{Experimental Design and Field Management}

The study was conducted at Unit Fertigasi Projek keusahawanan Ladang 10, UPM under rain shelter. A total of 6 rain shelters were used in this study. The study was designed in randomised complete block design (RCBD) with six replications. Each of the replication contain two treatments and labelled as TI for surface drip irrigation system and T2 as subsurface drip irrigation system. Each of the treatment contain four samples in each replication and the total of the samples were 48 (Figure 1).
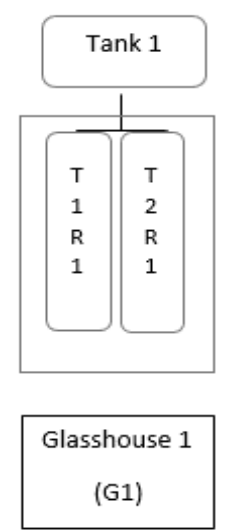
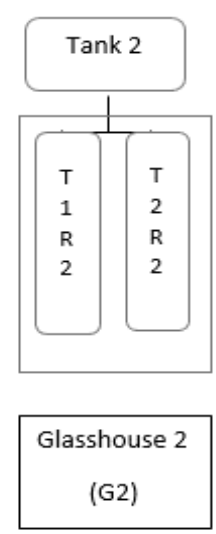
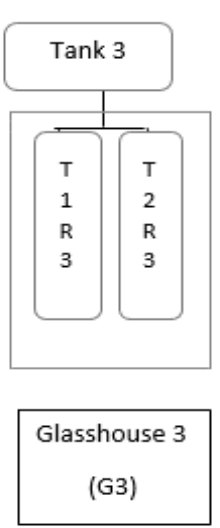
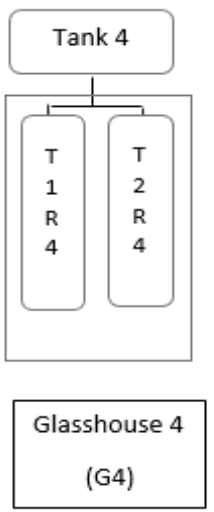
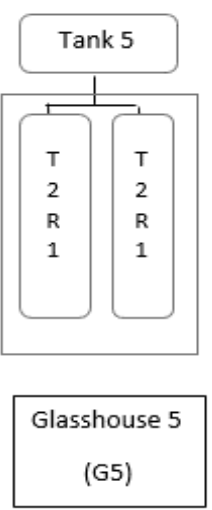

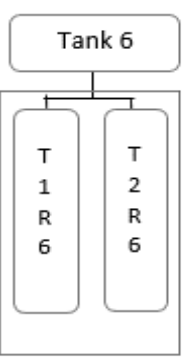

Glasshouse 6

(G6)

Figure 1. Arrangement of experimental design of rockmelon in the rain shelter.

For treatment 1, surface drip irrigation system was used as the irrigation method for the plants. Water was distributed through the point source drip emitters in form of water droplets. For this treatment, the pipeline and the drippers were located on the surface of growing medium. In treatment 2 , the rockmelon was irrigated through sub surface drip irrigation system. Point source drip emitter of $2 \mathrm{l} / \mathrm{hr}$ was used as water distributor for the plant. The pipeline and drip emitters were placed inside the growing medium for this treatment. The pipeline was buried in the soil at $5 \mathrm{~cm}$ depth from the surface. Each polybag will be irrigated 3 times per day and receive $200 \mathrm{ml}$ of fertigation water for each irrigation.

\subsection{Sample Preparation}

In this study, rockmelon was chosen as an experimental plant and all plants were planted in polybag with cocopeat as growing medium. As much as 48 rockmelon plants were 
planted in the polybag in this experiment. The fertigation system used the formulation of fertilizers A and B to provide nutrient to the plants to enhance the growth of rockmelon.

Rockmelon is an annual crop with 60-75 days of growth cycle after transplanting and commonly grown in glasshouse or under rain shelter. In this study the variety of rockmelon used was Melon F-1 Hybrid by SAKATA. The seed was sowed in tray seedlings using peat moss as the medium for seed sowing. Upon preparation for transplanting, 48 polybags were prepared using cocopeat as planting medium.

Before sowing the seeds in the seedling tray, the rockmelon seeds were soaked in the water first for 2-3 hours. The reason why the seed must be soaked in water is to soften the seed coat and remove the chemical around the seed. Later seeds were sow in the seedlings tray for 12-14 days. Peat moss was used as the medium for seed sowing. After sowing, the seed must be covered with black plastic or placed in covered place to avoid the water to easily evaporate until the shoot grow. The seeds were watered 3 times per day according to weather condition.

Due to transplanting, cocopeat was used as the growing medium. Cocopeat must be wet before transplanting. The rockmelon seedling aged 12-14 days were transplanted from seedling tray into the growing medium in the polybag.

\subsection{Irrigation Efficiency}

Irrigation system application efficiency is the amount of water stored in the root zone that is available to meet crop transpiration needs in relation to the amount of irrigation water applied to the field. The system is important to identify the achievement level of existing system applied so that further improvements can be made. Application efficiency is a performance that express how well an irrigation perform when is operated to deliver specific amount of water. Irrigation application efficiency formula can be expressed in equation (1):

$$
\mathbf{E a}=\frac{\mathbf{w s}}{\mathbf{W D}} \times 100
$$

Where,

$\mathrm{Ea}=$ irrigation application efficiency

$\mathrm{Ws}=$ water stored by irrigation

$\mathrm{Wd}=$ water delivered to the area being irrigated

\subsection{Data Collection}

The growth of rockmelon plant in each treatment is based on two irrigation methods which were surface and subsurface drip irrigations method. Data was collected during first week after transplanting until week six. The initial plan for data collection was until week 10 (until harvest), however due to pest and disease outbreak occurred at week 6 most of the trees were affected and had to be removed. Meanwhile, the ripe rockmelon fruits were harvested. 
The effect of growth rate on the two treatments were measured by taking the leaf length, leaf diameter and fruit circumferences using the measuring tape. The leaf length was measured from the end of leaf vein to the tip of leaf and leaf diameter was measured from side to side of the leaf. Four leaves were chosen randomly from a tree for measurements purposes. The fruit diameter was measured by taken the circumference of the fruit as soon as the trees started fruiting and the reading were recorded as weekly basis until week 6 . Fruit weight after harvest was not measured in this study as the rockmelon was only planted until 6 weeks due to the disease outbreak.

\subsection{Data analysis}

The effect of each treatment on the growth parameter: leaf length, leaf diameter and fruit diameter were analysed using Statistical Analysis Software (SAS). Analysis of Variance (ANOVA) was performed to find the significant effect of different irrigation methods to leaf diameter, leaf length and fruit circumference. Mean comparison using Least Significant Differences (LSD) test at $p<0.05$ was employed for mean comparison. Differences were considered significant when the $p$ value was $<0.05$.

\section{Results and Discussion}

\subsection{Leaf Diameter, Leaf Length, Fruit Circumferences}

Table 1 shows the result on plant growth for leaf diameter, leaf length and fruit circumferences of rockmelon from week 1 until week 6 after transplanting. During week 1 there was no significant difference for leaf diameter between T1 and T2. During week 6, result showed significant difference between treatments for leaf diameter. T1 which is surface drip irrigation show higher mean value compared to T2, subsurface drip irrigation. In addition, from other parameters which were leaf length and fruit circumferences, the result showed no significant differences between each treatment in week 1 and week 6 .

The usage of cocopeat as growing medium was the reason for the insignificant results as cocopeat was at maximum water holding capacity for each treatment T1 and T2 during measurements. Cocopeat is known for its high water holding capacity which can retain water in the fibrous materials at longer period. Thus, readily available water for plant uptake is available at all time especially when irrigation water is replenishing every day. Therefore, for both treatments, there were no significant difference in plant growth parameter due to high water holding capacity of cocopeat. However, based on leaf diameter, it can be concluded that T1 had better growth parameter suggesting that surface drip irrigation is a better method compared to subsurface drip irrigation.

It was found that the growth of rockmelon for surface drip irrigation is higher compared to subsurface drip irrigation. This is due to water was efficiently distributed from the drip to the plant which results in better growth since plants received enough water intake 
that were used for vegetative growth. However, due to the disease and pest outbreaks, the yield of rockmelon was not able to be collected.

Table 1. Leaf diameter, leaf length and fruit circumference in treatment T1: surface drip irrigation and T2: subsurface drip irrigation, data are means value $(n=48)$.

\begin{tabular}{ccccc}
\hline $\begin{array}{c}\text { Days after transplanting } \\
\text { (week) }\end{array}$ & Treatment & $\begin{array}{c}\text { Leaf diameter } \\
(\mathrm{cm})\end{array}$ & $\begin{array}{c}\text { Leaf length } \\
(\mathrm{cm})\end{array}$ & $\begin{array}{c}\text { Fruit circumference } \\
(\mathrm{cm})\end{array}$ \\
\hline Week 1 & $\mathrm{T} 1$ & $5.342 \mathrm{a}$ & $4.496 \mathrm{a}$ & $15.002 \mathrm{a}$ \\
& $\mathrm{T} 2$ & $5.300 \mathrm{a}$ & $4.703 \mathrm{a}$ & $16.665 \mathrm{a}$ \\
\hline Week 6 & $\mathrm{T} 1$ & $22.467 \mathrm{a}$ & $14.496 \mathrm{a}$ & $32.133 \mathrm{a}$ \\
& $\mathrm{T} 2$ & $20.933 \mathrm{~b}$ & $15.119 \mathrm{a}$ & $30.827 \mathrm{a}$ \\
\hline
\end{tabular}

Values in each column with same letter did not differ significant at $p<0.05$ according to LSD.

\subsection{Irrigation Application Efficiency}

The irrigation application efficiency for all treatments in the six rain shelters gave the same value of $25 \%$. The calculation of the irrigation application efficiency was done to show the efficiency of the irrigation between two treatments. This study show that both of the treatments achieved $25 \%$ of irrigation application efficiency resulting in no difference between the treatments. In general, the overall efficiency should be around $45 \%$ for good irrigation application. This experiment was done using the pre-installed set up from the Unit Fertigasi Projek keusahawanan Ladang 10, UPM provider, thus maintenance interference were limited. The poor water application efficiency may be due to the leakage from the drippers and lateral pipes occurred. However, despite the low efficiency, the usage of cocopeat had increased water availability in the medium as cocopeat can retain water longer in the pores (Ilahi \& Ahmad, 2017).

\section{Conclusions}

From this study, comparison of the rockmelon growth performance from the two treatments, surface drip irrigation (T1) and subsurface drip irrigation (T2) was done. For surface drip irrigation treatment, water was irrigated on the surface of the medium, while for subsurface drip irrigation treatment, drippers were buried $5 \mathrm{~cm}$ depth in the medium and water was dripped at the root zone. The outcome of this study shown that the effect of the treatments had significant difference for leaf diameter. However, for leaf length and fruit circumference there were no significant difference between treatments. Based on the result, it can be concluded that surface drip irrigation gave better result compared to subsurface drip irrigation due to the planting cultivation in polybags with cocopeat growing medium. 
It can be concluded that, the medium used for planting is the main factor that effected the irrigation and the growth of the rockmelon. Cocopeat was used as planting medium in this study. Cocopeat is commonly used as planting medium due to its ability to hold water in pores at higher rates and longer period (Ilahi \& Ahmad, 2017; Yahya et al., 2009). Thus, when the water is discharge from the drippers into the medium, water is still available in the cocopeat and it show no different between treatments.

Supplementary Materials: The following are available online at http://www.journals.hhpublisher.com/index.php/AAFRJ//xxx/s1, Figure S1: title, Table S1: title.

Author Contributions: Conceptualization, W.F.F. and N.N.C.; methodology, W.F.F. and M.F.A.; software, X.X.; formal analysis, W.F.F. and M.F.A.; writing — original draft, W.F.F. and M.F.A.; writing — review and editing, W.F.F. and N.A.H.

Funding: The fees was supported by Long Term Research University Grant (LRGS) of Universiti Putra Malaysia, Serdang, Selangor, Malaysia.

Acknowledgments: The researchers would like to thank LRGS Faculty of Agriculture, staffs of Taman Pertanian Universiti and Department of Agriculture Technology, Faculty of Agriculture UPM for their assistance.

Conflicts of Interest: The authors declare no conflict of interest, and also the funders had no role in the design of the study; in the collection, analyses, or interpretation of data; in the writing of the manuscript, or in the decision to publish the results.

\section{References}

Çolak Y. B., Yazar A., Gönen E., et al. (2018). Yield and quality response of surface and subsurface dripirrigated eggplant and comparison of net returns. Agricultural Water Management, 206, 165-175.

Ilahi W. F. F., \& Ahmad D. (2017). A study on the physical and hydraulic characteristics of cocopeat perlite mixture as a growing media in containerized plant production. Sains Malays, 46(6), 975-980.

Monteiro R. O. C., Coelho R. D., \& Monteiro P.F.C. (2014). Water and nutrient productivity in melon crop by fertigation under subsurface drip irrigation and mulching in contrasting soils. Ciência Rural, 44(1), $25-30$.

Şengül N., Çavuşoğlu O. Y. N. H. Ş., \& Doğan E. (2014). Yield and fruit quality response of drip-irrigated melon to the duration of irrigation season. Journal of Soil Water.

Sidhu H., Jat M., Singh Y., et al. (2019). Sub-surface drip fertigation with conservation agriculture in a ricewheat system: A breakthrough for addressing water and nitrogen use efficiency. Agricultural Water Management, 216, 273-283.

Wu D., Xu X., Chen Y., et al. (2019). Effect of different drip fertigation methods on maize yield, nutrient and water productivity in two-soils in Northeast China. Agricultural Water Management, 213, 200-211. 
Yahya A., Shaharom A. S., Mohamad R., et al. (2009). Chemical and physical characteristics of cocopeat-based media mixtures and their effects on the growth and development of Celosia cristata. American Journal of Agricultural and Biological Sciences, 4(1), 63-71.

Copyright $\odot 2020$ by Fazilah WFF, et al. and HH Publisher. This work is licensed under the Creative Commons

Attribution-NonCommercial 4.0 International Lisence (CC-BY-NC4.0) 